\title{
CORRESPONDENCE
}

The Archbishop and the neurosurgeon

W B Jennett, FRC

Economies through improved

dermatology services

H R Vickers, FRCP. . . .

The NHS is dead: long live the NHS

G W Roberts, FFCM..............46

The London hospitals scene

W J Lockley, MB ; R W Heslop, FRCS . . . . . . .46

Mobile chest radiography

O D Beresford, MD

The end of excellence?

A P Hall, MRCP; N D W Weaver.

Propranolol absorption

C F George, MD, and C M Castleden, MRCP . .47

General practitioner's role in management

of labour

J M English, MRCGP; H R Chapman, MRCGP

Gillian G Matthews, MRCOG; M J Aylett,

MRCGP; D G May, MB, DOBSTRCOG; H

Meadows, MRCGP.............47

Managing mild hypertension

R R H Lovell, FRACP, and others; S L O

Jackson, MD; D R Swinson, MRCP. . . . . . . .48
"Nurse consultants"

Jean Kelly, SRN

Chemoprophylaxis of malaria

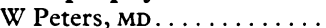

Risks of exotic infections

A D Macrae, frCPATH.............50

Comparative diagnostic accuracy of barium meal and endoscopy

J A H Forrest, MRCP, and R F A Logan,

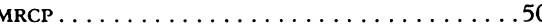

7 Labelling of foodstuffs for patients with coeliac disease

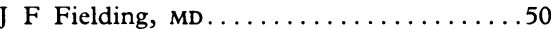

Toxocara infections and kennel workers D E Jacobs, PHD, and others..........51

Local gold toxicity

D C Dick, MRCP

Prevention of cross-infection

Beryl Jameson, FRCPATH, and others......51

L-Tryptophan and sexual behaviour

A D Broadhurst, FRCPSYCH, and B Rao, MRCPSYCH. . . . . . . . . . . . . 51

Community self-care

R J Cockerill, мв................52
Ferrous sulphate: danger to children

J R Saunders, FRCOG, and A W Ferguson,

FRCP...................... 52

FEIBA in haemophiliacs with factor VIII inhibitor

T Thomas, AIMLs, and others.........52

Low molecular weight dextran

D Honeybourne, MB ............52

BMA representation in hospitals

R J H Smith, frCs.............. 53

A "specialist" grade

G Dick, FRCP . . . . . . . . . . . . . . 53

Consultants' contract

G Behr, FRCP; D C Evered, MD, and R A L

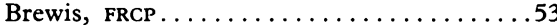

Hospital practitioner grade

R D M MacLeod, MRCPED . . . . . . . . . 54

NHS (Vocational Training) Act and returning British graduates

M F Harris, MB $\ldots \ldots \ldots \ldots \ldots \ldots \ldots \ldots \ldots \ldots \ldots$

Deputising services

M H Husain, MRCP................54

Pensions: cost-of-living increases

R D Rowlands, FRCs . . . . . . . . . . . . . . .54
Correspondents are urged to write briefly so that readers may be offered as wide a selection of letters as possible. So many are being received that the omission of some is inevitable. Letters should be signed personally by all their authors.

\section{The Archbishop and the neurosurgeon}

SIR,- - Several of the statements made by $\mathrm{Mr}$ Walpole Lewin (20 November, p 1234) in his Victor Horsley lecture on severe head injuries are at odds with the opinions of the Archbishop of Canterbury, as recently expressed, and of several other churchmen before him. Mr Lewin states: "To suggest that one necessarily has to be conscious and speaking to make a contribution to others is an unwarranted assumption." But the Dutch Reformed Church stated several years ago that life in a Biblica sense presupposes the possibility of communication, and that once there is no chance of recovery for an unresponsive patient he has ceased to be a human being with his own individuality and that it is then ethically justified to stop medical treatment. Mr Lewin also says, "I have always objected to the word 'vegetable' because it carries the implication that these patients are not making any further contribution." But it was the Bishop of Durham, addressing the BMA Annual Clinica Meeting in 1972, who said, "We should avoid maintaining a semblance of life in people who can never become more than living vegetables.' And Mr Lewin says, "It has not been our normal policy to switch off ventilators .... and most of [the patients] die within six days." But there have been repeated statements in the medical and lay writings in recent years on brain death which indicate general acceptance of the view that to continue ventilation of a brain-dead patient day after day is to deprive that patient of death with dignity and to prolong needlessly the distress of relatives. It is ironic that $\mathrm{Mr}$ Lewin's lecture was entitled "Changing attitudes to the management of severe head injuries"; in fact it betrays an unchanging and now reactionary attitude. I have recently commented that "increasing awareness of the importance of the quality of life in survivors of treatment is evident both in the health professions and in society at large. For various reasons, however, doctors tend to remain traditional in their approach and even when relatives and nurses agree that it would be more sensible and humane to let events take their natural course, the doctor is often the one who fights on." The Archbishop's and Mr Lewin's statements provide a nice illustration of this point.

Modern technology gives doctors the capability of prolonging the lives of many patients who would previously have died rapidly; such life may be sustained only for days but sometimes for months or years. Of course some patients rescued by elaborate and expensive intervention recover well, but others survive in a hopelessly crippled state. To pretend that this seldom happens or that when it does it should be accepted as in some way worth while makes it more difficult to debate the issue-but it does not solve the problem. Only this week I learnt about an investigation in Japan which revealed over 100 vegetative patients surviving in one area of that country the commonest cause was head injury and many of the victims survived for years in that state. I have recently discussed in detail the dilemma of allocating resources to the care of the badly brain-damaged. ${ }^{2}$ This was in an American journal because this dilemma is not limited to countries with manifest economic difficulties in providing health care. A recent report from the Massachusetts General Hospital $^{3}$ highlights the economic consequences of the traditional policy which $\mathrm{Mr}$ Lewin is at pains to defend. A year after critical care treatment only $12 \%$ of 226 patients were restored to their pre-illness state; the costs in fatal cases were twice as great as for those patients who made a full recovery. The authors emphasised that realistic allocation of the limited resources available for such treatment requires doctors to select patients-both for the initiation of rescue procedures and for their subsequent withdrawal. Unless this is done it is inevitable that other patients whose condition is not hopeless will be denied the chance of recovery because the doctors are already deploying all available machinery (or beds, or nurses) on maintaining life support for patients who cannot be expected to benefit.

It may be reassuring to some members of society to know that their doctors will fight doggedly on, despite the pleas of bishops to moderate their therapeutic zeal. But I am impressed by how often society is now calling doctors to order-is questioning their conventional wisdom and their rights to make these important decisions. And I refer not only to public platforms and published statements but also to relatives encountered in the course of treating critically ill patients in hospital. It might be more reassuring for society to know that Mr Lewin's view is probably now a minority one, even among neurosurgeonswho frequently face the tragedy of young brains irreparably damaged by a moment's violence.

BRYAN JENNETT

Department of Neurosurgery, Institute of Neurological Sciences, General Hospital,

Glasgow

Jennett, B, Lancet, 1976, 2, 1235.

2 Jennett, B, Archives of Neurology, 1976, 33, 595. cullen, D J, et al, New England fournal of Medicine, 